\title{
A experiência do Prodema na pós-graduação brasileira: ciência para a sustentabilidade na UFC
}

\section{The experience of PRODEMA in Brazilian graduate education: science for sustainability at UFC}

\section{La experiencia del PRODEMA en el posgrado brasileño: ciencia para la sostenibilidad en la UFC}

Laudemira Silva Rabelo, doutoranda e mestre em Desenvolvimento e Meio Ambiente junto ao Programa de Pós-Graduação em Desenvolvimento e Meio Ambiente (Prodema) da Universidade Federal do Ceará. Endereço: Centro de Ciências, bloco 902, Campus do Pici. CEP: 60455-970 - Fortaleza, CE. Telefone: (85) 3366-9781. Fax: (85) 3366-9466. E-mail: laudemira@yahoo.com.br.

Melca Silva Rabelo, doutoranda e mestre em Desenvolvimento e Meio Ambiente junto ao Prodema. Endereço: Centro de Ciências, bloco 902, Campus do Pici. CEP: 60455-970-Fortaleza, CE. Telefone: (85) 3366-9781. Fax: (85) 3366-9466. E-mail: msilvarabelo@yahoo. com.br.

George Satander Sá Freire, doutor em Geologia pela Universidade de Nantes, França, e professor associado IV da Universidade Federal do Ceará. Endereço: Centro de Ciências, bloco 902, Campus do Pici. CEP: 60455-970 - Fortaleza, CE. Telefone: (85) 3366-9781. Fax: (85) 3366-9466. E-mail: satanderfreire@gmail.com.

Vládia Ponto Vidal de Oliveira, doutora em Engenharia Agrícola pela Universidad de Almería, Espanha, e professora associada I da Universidade Federal do Ceará. Endereço: Centro de Ciências, bloco 902, Campus do Pici. CEP: 60455-970 - Fortaleza, CE. Telefone: (85) 3366-9781. Fax: (85) 3366-9466. E-mail: vladia.ufc@gmail.com.

Patrícia Verônica Pinheiro Sales Lima, doutora em Economia Aplicada pela Universidade de São Paulo (USP) e professora 
associada da Universidade Federal do Ceará. Endereço: Centro de Ciências, bloco 902, Campus do Pici. CEP: 60455-970 - Fortaleza, CE. Telefone: (85) 3366-9781. Fax: (85) 3366-9466. E-mail:pvpslima@ gmail.com.

\section{Resumo}

A sustentabilidade insere-se em um contexto em que é necessário desvincular-se da visão disciplinar e adentrar na construção do saber interdisciplinar e complexo. A Rio + 20 trouxe à tona a urgência da mudança para um sistema econômico inclusivo denominado Economia Verde. Essa transformação irá demandar novos profissionais e cientistas que possam melhor transpor as barreiras para a real mudança. Dessa forma, o presente artigo tem como objetivo apresentar as contribuições do Programa de Pós-Graduação em Desenvolvimento e Meio Ambiente, da Universidade Federal do Ceará, na construção do saber interdisciplinar frente às questões relacionadas ao desenvolvimento sustentável no ensino de pós-graduação e na formação de profissionais aptos a contribuírem para a efetivação dos ideais propagados pela educação para a sustentabilidade.

Palavras-chave: Sustentabilidade. Pós-Graduação. Interdisciplinaridade. Prodema.

\section{Abstract}

Sustainability is inserted in a context in which it must be extricated from disciplinary vision and included into the construction of complex and interdisciplinary knowledge. The Rio +20 raised the urgency of moving to an inclusive economic system called Green Economy. This transformation will require new professionals and scientists that can better overcome barriers to real change. Thus, this paper aims to present the contributions of the Graduate Program in Environment and Development at the Federal University of Ceará (UFC) in the construction of interdisciplinary knowledge in the face of issues related 
to sustainable development arising in the context of graduate education and professional training.

Keywords: Sustainability, Graduate Study, Interdisciplinarity, PRODEMA.

\section{Resumen}

La sostenibilidad forma parte de un contexto en el que es necesario desvincularse de la visión disciplinaria y adentrar la construcción del conocimiento interdisciplinario y complejo. La cumbre Río + 20 planteó la urgencia de hacer un cambio hacia un sistema económico inclusivo llamado “Economía Verde”. Esta transformación requerirá de nuevos profesionales y científicos que puedan superar de una mejor forma los obstáculos para que haya un verdadero cambio. Por lo tanto, este trabajo tiene por objetivo presentar los aportes del Programa de Posgrado en Desarrollo y Medio Ambiente de la Universidad Federal de Ceará, en la construcción del conocimiento interdisciplinario frente a cuestiones relacionadas con el desarrollo sostenible en la enseñanza de posgrado y en la formación de profesionales capaces de contribuir a la realización de los ideales propagados por la educación para la sostenibilidad.

Palabras clave: Sostenibilidad. Posgrado. Interdisciplinariedad. PRODEMA.

\section{Introdução}

A complexidade dos problemas relacionados à sustentabilidade foge dos métodos positivistas e remete-se à interdisciplinaridade e ao pensamento sistêmico. Analisá-la perpassa pela necessidade de um conhecimento amplo da capacidade de sustentação da Terra e dos processos que possam prejudicar ou estimular a continuidade da vida. Configura-se imprescindivel uma nova forma de pensar que possibilite 0 conhecimento das propriedades sistêmicas ou emergentes dos sistemas que compõem a relação sociedade-natureza. 
A Rio+20 fomentou o debate sobre a transição para um modelo econômico inclusivo denominado Economia Verde, que irá demandar a construção de novos paradigmas. A sua aplicação exige que haja mudanças nos setores produtivos e na sociedade, surgindo, dessa forma, a necessidade de se inserir a questão do desenvolvimento sustentável nos currículos acadêmicos das universidades, locais tradicionais de formação de recursos humanos. Preparar o novo profissional e estimular a criação de ciência e tecnologia capaz de transpor as barreiras existentes para a efetivação da Economia Verde é o grande desafio da universidade. Tal desafio demanda urgência na implementação dos princípios inseridos na educação para o desenvolvimento sustentável.

Nesse contexto, fica clara, também, a urgente necessidade de formação de docentes conhecedores do arcabouço conceitual do Desenvolvimento Sustentável e aptos a incorporar mudanças nas disciplinas tradicionais. Essa é uma das propostas do Programa de Pós-Graduação em Desenvolvimento e Meio Ambiente (Prodema).

O presente artigo tem como objetivo apresentar as contribuições do Programa de Pós-Graduação em Desenvolvimento e Meio Ambiente, da Universidade Federal do Ceará, na construção do saber interdisciplinar frente às questões relacionadas ao desenvolvimento sustentável no ensino de pós-graduação e na formação de profissionais capazes de promoverem a efetivação dos ideais propagados pela educação para a sustentabilidade.

\section{Ensino superior para o desenvolvimento sustentável}

A importância da educação nas questões ambientais tem suas raízes na Declaração de Estocolmo, documento resultante da Cimeira da Terra, em 1972, que definiu o termo educação ambiental e o seu propósito de conscientização ecológica do cidadão comum. Dentre as suas diversas recomendações, foi estabelecido que a UNESCO ${ }^{1}$ e outras instituições internacionais competentes adotassem disposições

1 United Nations Educational, Scientific and Cultural Organization. necessárias para a criação de um programa educativo internacional de educação interdisciplinar formal e não formal, relativo ao meio ambiente. 
Em 1975, foi criado o Programa Internacional de Educação Ambiental (Piea) com a finalidade de desenvolver o conhecimento e suscitar ações que permitissem contribuir para a gestão e proteção ambiental. Trabalho pioneiro, o Piea consolidou a preocupação crescente dos habitantes do planeta com as questões ambientais. Porém, nesse primeiro momento, teve melhor absorção na estrutura curricular dos ensinos fundamental e médio das escolas.

De acordo com as recomendações da Declaração de Estocolmo, o Pnuma² e a UNESCO realizaram o I Seminário sobre Universidade e Meio Ambiente para a América Latina e o Caribe, em Bogotá, Colômbia, no período de 28 de outubro a 01 de novembro de 1985. Foi a primeira tentativa de diagnosticar o grau de avanço dos programas ambientais no ensino superior e assim promover trocas de experiências, discussão de conceitos, orientações e incorporações de critérios sobre a dimensão ambiental nas práticas acadêmicas e investigativas. Em dezembro de 2002, a Assembleia Geral da ONU aprovou a Resolução 57 / 254, em que declarou o período de 2005-2014 como a Década das Nações Unidas da Educação para o Desenvolvimento Sustentável (DEDS).

A educação, que tem como objetivo despertar a consciência crítica sobre os problemas que afetam a relação sociedade-natureza, foi designada como fundamental para a efetivação da transição para o desenvolvimento sustentável. Integrar valores, atividades e princípios inerentes ao desenvolvimento sustentável em todas as formas de educação e contribuir para uma mudança de atitude, comportamentos e valores que possam garantir um futuro sustentável em termos sociais, ambientais e econômicos (UNESCO, 2007) é o objetivo audacioso da Década das Nações Unidas da Educação para o Desenvolvimento Sustentável, que não deve ser confundida com Educação Ambiental. "Educação para o desenvolvimento sustentável lida com a complexa fusão das questões relevantes a sociedade, ao meio ambiente e a economia, preparando pessoas para enfrentar e encontrar soluções para os problemas que ameaçam a sustentabilidade do planeta” (UNESCO, 2007, p. 6).

A base "recursos naturais" é prioritária para ambas, mas a Educação Ambiental enfatiza esse viés enfocando a administração

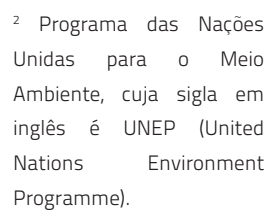


desses recursos, seja pela conservação ou preservação ambiental. Enquanto a Educação para o Desenvolvimento Sustentável traz um contexto mais amplo dessa relação sociedade-natureza ao pontuar outros itens que também interagem com as perspectivas socioculturais e ambientais e as questões sociopolíticas e econômicas, como podem ser vistas no Quadro 1.

Quadro 1. Aspectos tratados pela educação para o Desenvolvimento Sustentável

\begin{tabular}{|l|l|l|}
\hline \multicolumn{1}{|c|}{$\begin{array}{c}\text { Perspectivas } \\
\text { Socioculturais }\end{array}$} & \multicolumn{1}{c|}{$\begin{array}{c}\text { Perspectivas } \\
\text { Ambientais }\end{array}$} & $\begin{array}{c}\text { Perspectivas } \\
\text { Sociopolíticas e } \\
\text { Econômicas }\end{array}$ \\
\hline $\begin{array}{l}\text { - Direitos humanos } \\
\text { - Paz e Segurança }\end{array}$ & $\begin{array}{l}\text { - Recursos Naturais } \\
\text { (água, energia, } \\
\text { agricultura e }\end{array}$ & $\begin{array}{l}\text { - Redução da Pobreza } \\
\text { - Responsabilidade das } \\
\text { Empresas }\end{array}$ \\
- Igualdade de Gênero & biodiversidade) \\
- Diversidade Cultural & - Mudanças Climáticas \\
Intercultural & - Desenvolvimento & Mercado \\
- Saúde & Rural & \\
- Governança & - Urbanização & \\
& Sustentável & \\
& Prevenção e & \\
& Diminuição de & \\
& Desastres & \\
\hline
\end{tabular}

Fonte: UNESCO $(2005 ; 2007)$.

Revisão é a palavra que solicita a educação. É o vetor para promover mudanças não somente nas suas várias dimensões - educação formal ${ }^{3}$, não formal ${ }^{4}$ e informal ${ }^{5}$-, mas também na sua capacidade de formar competências que incentivem os alunos não somente a buscarem, mas promoverem, uma sociedade sustentável. Para tal, a efetivação da Educação para o Desenvolvimento Sustentável (EDS) necessita conter determinadas características estruturais, entre elas:

Conteúdo com inclusa na educação de uma instituição de ensino.

Conteúdo com metodologia, mas fora de uma instituição de ensino. ${ }^{5} \mathrm{O}$ repasse dessa educação não é sistematizado, nem possui metodologia, como nas relações cotidianas. (TOZONI-REIS, 2004). a) Inserir, de forma interdisciplinar e holística, o Desenvolvimento Sustentável, que necessita perpassar de forma integrada por todo o currículo e não como disciplina à parte;

b) Compartilhar valores e princípios fundamentados pelo Desenvolvimento Sustentável;

c) Desenvolver o pensamento crítico e a capacidade de encontrar solução para os desafios em relação ao Desenvolvimento Sustentável; 
d) Utilizar uma multiplicidade de métodos pedagógicos e analíticos para se moldar o processo ao Desenvolvimento Sustentável;

e) Estimular o processo participativo de tomada de decisão;

f) Aplicar no cotidiano as experiências de aprendizagem para o Desenvolvimento Sustentável; e

g) Contextualizar os problemas locais e globais na busca pelo Desenvolvimento Sustentável (UNESCO, 2005).

O papel de capacitar pessoas, principalmente, para as necessidades do mercado de trabalho não resume o projeto de ensino das universidades. A ciência e a tecnologia merecem o seu destaque. Enquanto a ciência é capaz de fornecer meios para se entender o mundo e os limites do ser humano no planeta, a tecnologia proporciona ferramentas para mudanças, inclusive de paradigmas. E essas visões podem ser aplicadas nos cursos de pós-graduação, “[...] concebidos para treinar os responsáveis por decisões” (AGENDA 21 GLOBAL, 2012, cap. 36).

Uma compreensão científica de sustentabilidade, conjuntamente com novos métodos inter e transdisciplinares de avaliações, conduzirá a sociedade a um processo de transição para o desenvolvimento sustentável. Entretanto, se faz necessário fortalecer as capacidades científicas (Ibidem, cap. 35), para que possam responder às novas necessidades da sociedade, cada vez mais complexas. E se é por meio da educação superior que se tem acesso à ciência e à tecnologia, precisa-se então ser repensada a sua função, que tem sido modificada a depender da própria evolução da sociedade.

Com esse olhar surgiu a Parceria Global de Ensino Superior para a Sustentabilidade (GHESP), de que constam a Associação Internacional de Universidades, o Campus Copernicus, a UNESCO e a Associação da Universidade de Líderes para um Futuro Sustentável, que, em esforço conjunto, promovem uma melhor compreensão e aplicação da inserção do desenvolvimento sustentável nas universidades e nos institutos de ensino superior do desenvolvimento sustentável, por meio de uma abordagem interdisciplinar em seus currículos no ensino, na pesquisa e 
extensão, como resposta ao capítulo 36 da Agenda 21 Global (UNESCO, 2012).

O caminho para uma sociedade sustentável perpassa pela universidade, instituição que nem sempre teve o formato hoje conhecido, bem como não é unificada de forma global. Embora conste, na maioria das universidades, o tripé ensino, pesquisa e extensão, ela não surgiu com essa concepção estrutural e nem com a função social atual. Evoluiu com os anseios e as dificuldades dos seus diversos atores sociais e, hoje, necessita de mudanças, tais como a inserção da interdisciplinaridade na formação de seus profissionais, algo que os orientaria na compreensão desse novo mundo - mais complexo e dinâmico - e em proposições de soluções à insustentabilidade vigente.

\section{Das certezas disciplinares à busca interdisciplinar}

O advento, na França, da Universidade napoleônica - a Universidade Imperial - pela Lei de 10 de maio de 1806 aboliu a instituição universidade medieval e instituiu faculdades superiores compartimentadas, com importância à colação de grau e ao diploma. Seus novos membros, não mais jesuítas devotos a uma igreja e sim ao Estado, são obrigados, sob juramento, a obedecer aos estatutos e a sujeitar-se ao Imperador. A formação universitária passa a não ser mais em busca das certezas da ciência, e sim por uma formação profissional, cujo diploma é requisito para o exercício de uma profissão (ROSSATO, 1998).

A criação da Universidade de Berlim, em 1809, trouxe algo novo para o conceito de universidade moderna, ao incorporar a pesquisa como um instrumento, conjuntamente com o ensino, para se atingir o desenvolvimento da ciência. A valorização da pesquisa fez desse modelo de universidade uma corporação de cientistas, que gozavam de liberdade de expressão no exercício do ensino - ação complementar à pesquisa (Ibidem). Esse modelo de universidade abriu o caminho para a universidade contemporânea, exportando essa nova estrutura para diversas outras mundialmente, que também adotaram a pesquisa como prioridade e o ensino como seu complemento, ou simplesmente 
a inseriram, conjugando a tríade acadêmica - ensino, pesquisa e extensão.

A Revolução Industrial e o capitalismo influenciaram bastante a instituição universidade, ao solicitar cada vez mais conhecimentos úteis e de aplicação imediata. Nesse caminhar, modificou-se o cenário de autonomia da ciência, que se tornou porosa à política, deixando-se penetrar pela economia. Ao aceitar profissionalizar-se, passou a definirse como uma atividade orientada não tanto pelo desejo da verdade, mas pela capacidade de produção de resultados práticos imediatamente aplicáveis na esfera política, militar ou econômica. A instituição universidade moderna trouxe não somente a função formadora de indivíduos, mas também o local de pesquisa e a produção de novos conhecimentos prioritariamente para a sua região ou país. Percebe-se assim um novo olhar dado pelo Estado ao ensino superior, em especial à pesquisa.

O fato de integrar a produção científica aos processos produtivos, consequentemente, moldou um novo mundo e alavancou 0 progresso econômico (LEFF, 2000; 2002), inicialmente de forma local e, posteriormente, global, trazendo novas responsabilidades para a ciência, que anteriormente buscava apenas entender as causalidades das coisas. Assim, a ciência nas universidades inclui-se (ou deveria incluir-se) como área prioritária de qualquer país, percorrendo caminhos direcionados pelas necessidades governamentais e de mercado, por meio dos diversos editais que a fomentam.

Hoje, somos convidados a usar tudo o que a ciência constrói para facilitar a vida humana, reconhecendo, assim, nossa dependência da ciência com a política, com a economia ou com o cotidiano da vida. Se a ciência se modifica para a política, a economia ou para o nosso dia a dia, as universidades, ao longo de sua história, tentaram acompanhar essas transformações e aceitar novas abordagens dessa realidade, não mais vista apenas de forma disciplinar, por abranger cada vez mais problemas complexos. E, sendo os problemas ambientais discrepâncias entre o que o mundo é e o que deveria ser (GROOT, 1992), essa mesma ciência precisa ser capaz de promover a transição para a sustentabilidade - em direção 
a padrões de desenvolvimento que promovam o bem-estar humano ao mesmo tempo em que conservem a vida dos diversos ecossistemas.

O desenvolvimento sustentável, que tem como cenário a complexidade das inter-relações sociedade-natureza, demanda novos conhecimentos e novas formas de análises dessa realidade, diferente da racionalidade tecnológica e da fragmentação do conhecimento. O método científico, que norteia o modelo predominante da ciência moderna, fundamentado nos pressupostos positivistas, foi necessário para um conhecimento e avanço tecnológico especializado, mas deixou como legado uma cegueira disciplinar, advinda da fragmentação do saber e impotente diante de problemas acentuados ou gerados pelo progresso.

Assim, são duas as possíveis estratégias para a análise dos problemas ambientais. A primeira seria recorrer à especialização de cada disciplina de conhecimento e buscar soluções adequadas. Nesse olhar, escolher uma única disciplina, por mais promissora que seja, inviabiliza a sua correta análise, devido ao fato de a questão ambiental transitar pelas diversas áreas de conhecimento. A segunda seria trazer as várias disciplinas para uma convergência, algo concretizado pela interdisciplinaridade (BÜRGENMEIER, 2005).

A inserção da Educação para o Desenvolvimento Sustentável no ensino superior traz implícita a necessidade também dessa forma holística e interdisciplinar de ver o mundo, algo muitas vezes esquecido e controverso para as universidades.

\section{a. A interdisciplinaridade como categoria de reflexão à sustentabilidade}

O termo interdisciplinaridade tem seus primeiros relatos na década de 1930, como um atalho para pesquisas que cruzaram disciplinas, descritas no Social Science Research Council, existindo exemplos em pesquisas agrícolas na década de 1940 e experiências educativas nos anos de 1960 e 1970 (KLEIN, 1990). Mas foi com Jean William Fritz Piaget (1896-1980), defensor da abordagem interdisciplinar para a investigação epistemológica, no I Seminário Internacional sobre Pluri e Interdisciplinaridade, realizado na Universidade de Nice, na 
França, em 1970 (LEFF; MONTES, 1986), que a interdisciplinaridade ganhou força.

O movimento interdisciplinar iniciou-se na Europa no final da década de 1960, conjuntamente com a crise econômica e política do sistema capitalista na década de 1970; isto é, a crise do petróleo. Os movimentos de cunho político-cultural de oposição ao modelo taylorista/ fordista, a competitividade entre os países - organizados por blocos -e as mudanças tecnológicas que traziam uma nova realidade não eram mais compreendidos pelo modelo educacional vigente. Os movimentos estudantis, iniciados na França, Alemanha e Itália, exigiam modificações no estatuto das universidades, em oposição à alienação da academia frente às questões do cotidiano da sociedade e às organizações curriculares que privilegiavam excessivamente a especialização (KLEIN, 1990; FAZENDA, 1994; ALVARENGA; SOMMERMAN; ALVAREZ, 2005; ROHDE, 2005).

Nesse período, a competição acirrada forçou as empresas a se reestruturarem para intensificarem uma produção pautada em um modelo de gestão que não aceitava desperdício - surgia, dessa forma, o modelo de produção enxuta, que exigia qualidade total; e, para tal, necessitaria do comprometimento e da colaboração dos funcionários por meio da difusão de suas experiências e seus conhecimentos -, incentivando-se os trabalhos em equipe. Nesse novo modelo, a formação disciplinar não mais cabia, pois o profissional precisava combinar a flexibilidade da produção com a dos mercados, isto é, a multifuncionalidade que vinha como condição necessária para assegurar rentabilidade e produtividade (MANGINI; MIOTO, 2009).

Resposta à formação de um novo indivíduo capaz de integrar, colaborar com e coordenar uma postura mais flexível diante de um mundo em mudanças, a interdisciplinaridade teve em Georges Gusdorf (1912-2000) um grande incentivador dessa proposta, que a definiu como o resultado do diálogo entre especialistas e da interação afetiva entre as disciplinas. O sucesso da interdisciplinaridade dependeria do domínio aprofundado de cada uma das disciplinas participantes, para que se pudesse chegar à construção do todo, não anulando assim a 
disciplinaridade (ALVARENGA; SOMMERMAN; ALVAREZ, 2005; MINAYO, 1994).

O movimento interdisciplinar iniciava sua jornada influenciado tanto pelas demandas sociais, que viam no conhecimento especializado a ligação direta entre a racionalidade tecnológica e o comprometimento com a lógica de mercado, bem como pela própria evolução do discurso científico, isto é, por influências externas e internas ao pensamento científico (FOLLAN, 1995). A produção interdisciplinar era solicitada a adentrar o seu conhecimento na aplicação e no planejamento do desenvolvimento econômico, enquanto, ao mesmo tempo, fenômenos interdisciplinares não eram abarcados por objetos teóricos disciplinares - o real pertencia à ciência não como objeto isolado, mas como a reunião das partes de um todo. Pelo fato de os problemas de pesquisa do mundo real raramente surgirem ordenados em categorias disciplinares e muito menos suas soluções (REPKO, 2012), a interdisciplinaridade propõe-se como avanço do conhecimento para a resolução dos problemas do novo mundo, dentre eles os ambientais, originando-se assim as Ciências Ambientais (LEFF, 2002).

A relação sociedade-natureza tornou-se objeto de estudo das Ciências Ambientais (GROOT, 1992). Contudo, natureza e sociedade não são conceitos e nem objetos de nenhuma ciência, não constituindo termos de articulação científica (LEFF, 2002). Sua articulação darse-á por sua interação e seu efeito no mundo real, ao transformar ecossistemas; por exemplo, incorporar a natureza ao processo produtivo.

A problemática ambiental, acentuada nas últimas décadas com a crise da civilização, questiona a racionalidade econômica e a tecnologia dominante, em que ambos foram impulsionados por uma ciência positivista que priorizou o fracionamento do conhecimento em busca dos progressos científico, tecnológico e econômico. Hoje, essa mesma ciência é convidada a revisitar o seu legado e rever o modelo de progresso, que tem como fator limitante não somente a natureza, mas a própria sociedade que também é parte integrante desse sistema.

São diversas as razões para a existência da interdisciplinaridade, tais como a unidade da realidade, a intercepção ou a similitude de 
diferentes objetos teóricos, a conveniência de mais conhecimento como suporte de uma intervenção social, a consciência dos investigadores da existência de outros discursos "complementares" ao seu, a percepção de que "pequenas coisas" podem ser importantes para estar e agir e, principalmente, a criação de um ambiente social favorável à troca de saberes (POMBO, 2005).

A interdisciplinaridade tem-se intensificado nos últimos anos e está fundamentada em três áreas, com dinâmicas próprias: a) investigação científica; b) ensino-educação; e c) ação (LEFF, 2000; PIMENTA, 2008). Na investigação científica, surgem os fenômenos interdisciplinares, permeados por distintas lógicas de apreensão, que solicitam os diversos campos do saber para se gerar conhecimento, em que se ressalta como exemplo a interdisciplinaridade ambiental.

Assim, questões ambientais nos remetem necessariamente a um olhar interdisciplinar, por haver uma insuficiência do conhecimento fragmentado para o tratamento da complexidade ambiental, em que diferentes intervenções acontecem em escalas espaços-temporais também diferenciadas (PENA-VEJA; ALMEIDA, 1999). Contudo, nem todo agrupamento de pessoas de diferentes especializações pode ser considerado uma equipe interdisciplinar.

Para tal, interdisciplinaridade precisa ser conhecida conceitualmente a partir de algumas definições:

[...] é um método de pesquisa e de ensino suscetível de fazer com duas ou mais disciplinas interajam entre si. Esta interação pode ir da simples comunicação das idéias até a integração mútua dos conceitos, da epistemologia, da terminologia, da metodologia, dos procedimentos, dos dados e da organização da pesquisa (JAPIASSU, 2006, p. 109).

[...] qualquer forma de combinação entre duas ou mais disciplinas com vista à compreensão de um objecto a partir da confluência de pontos de vista diferentes e tendo como objectivo final a elaboração de uma síntese relativamente ao objecto comum. A interdisciplinaridade implica, portanto, alguma reorganização do processo de ensino/aprendizagem e supõe um trabalho continuado de cooperação dos professores envolvidos (POMBO; LEVY; GUIMARÃES, 1993, p. 13). 
Conceitualmente, um estudo interdisciplinar é um processo que responde a uma pergunta, resolve um problema ou é solução de um tema amplo ou complexo para ser tratado por uma única disciplina, baseandose em perspectivas disciplinares, mas sendo capaz de integrar os seus conhecimentos por meio de uma perspectiva mais abrangente. Pode ser acrescentado que, em pesquisas interdisciplinares, além da necessidade crítica e autocrítica, existe também uma visão integrada e propositada do problema. Estudos interdisciplinares dependem das disciplinas para as suas perspectivas, percepções, seus dados, conceitos, suas teorias e seus métodos no processo de desenvolvimento de uma compreensão interdisciplinar de um problema particular, mas não de uma classe de problemas semelhantes (REPKO, 2012).

Essas demandas geram adequações metodológicas, técnicas e de linguagens de cada disciplina em uma tarefa que se caracteriza por um processo dialético - quando traz contradições que caracterizam o esforço em inter-relacionar os saberes -, sistêmico - por obrigar uma análise dinâmica entre relações e complementos -, seletivo - ao buscar para cada problema suas categorias críticas - e interativo e aberto (REPKO, 2012).

Para aprofundar um pouco mais a abordagem, é necessário lembrar que nem todas as interdisciplinaridades são iguais. Se existem divergências sobre a definição, elas se refletem na finalidade de investigação e educação. Klein (1990) apresenta duas categorias de interdisciplinaridade: a) endógena, que se preocupa com a produção de novos conhecimentos; e b) exógena, que interroga as disciplinas sobre as demarcações que se aplicam à vida real e exige da universidade sua função social.

Paviani (2008) também apresenta a interdisciplinaridade instrumental como uma atividade de solução de problemas que podem ser projetados para atender às demandas da indústria e do governo, enquanto a interdisciplinaridade conceitual está preocupada com as questões teóricas, epistemológicas do conhecimento. No entanto, essas distinções apresentadas não são absolutas, por não ser a interdisciplinaridade um fenômeno homogêneo e uniforme, e sim com diversos níveis e graus de afetividade. 
A interdisciplinaridade pode ser trabalhada em um tema ou objeto de estudo, em que as disciplinas, duas ou mais, intencionalmente se relacionam, sem perderem suas características, mas somando-as para o conhecimento de uma forma mais abrangente e sistêmica. Contudo, a construção de um novo objeto científico a partir da colaboração de diversas disciplinas, e não apenas como o tratamento comum de uma temática, é um processo que se consumou em poucos casos na ciência e que não são generalizáveis a ponto de permitir depreender uma metodologia aplicável para produzir efeitos similares em outros campos do conhecimento e da pesquisa (LEFF, 2002).

Percebe-se que a interdisciplinaridade é também um resgate do ser humano com a síntese projetada do mundo real, precisando também de uma reflexão sobre as atitudes que se constituem como interdisciplinares, para que não ocorra desvio de sua prática (TRINDADE, 2008).

Embora a interdisciplinaridade tenha tido um crescimento dentro do pensamento científico, não existe a obrigatoriedade de seu uso em todos os objetos científicos analisados; isso porque também não existe a pretensão de substituir a disciplinaridade e a especificidade necessária em determinadas áreas da ciência, mas especificamente em sistemas complexos, dinâmicos e não-lineares, como são todos os envolvidos na questão ambiental, nos quais intervêm processos de diferentes racionalidades, ordens de materialidade e escalas-temporais (UNESCO / UNEP, 1985).

A solução para a transição ao desenvolvimento sustentável não poderá advir apenas de uma gestão racional da natureza e dos riscos de mudanças globais. O conhecimento gerado pelo mundo tem contribuído para a permanência do modelo de desenvolvimento global. E se anteriormente para a ciência não cabiam os limites da natureza, o tempo da matéria e da história ou mesmo a diversidade, hoje, a complexidade reabre todas essas reflexões sobre o tempo no real, que se manifesta na irreversibilidade dos processos, agora distantes do equilíbrio e influenciados pelo ser cultural, o homem (MORIN, 2000). 
O novo ser precisa compreender a complexidade das inter-relações desse novo sistema - os mundos de vida. Isso porque mesmo que se consiga um elevado nível de capacidade crítica, nenhum sujeito individual conseguirá solucionar sozinho nenhuma crise. Esse esforço é sempre acumulativo e social, enquanto o conhecimento é relativo, parcial e incompleto (FOLLAN, 1995).

O desenvolvimento sustentável, como fenômeno complexo, solicita estudos interdisciplinares, holísticos e sistêmicos, adotados não apenas por pequenos grupos de cientistas desbravadores, para que se firme em longo prazo e possibilite integrações tanto locais como globais.

Nesse viés, os programas de pós-graduações no Brasil foram pioneiros ao inserirem a interdisciplinaridade no enfoque temático do meio ambiente, destacando-se, por cronologia, os seguintes cursos de pós-graduação brasileiros: Programa em Ciência Ambiental (Procam), originado em 1989, pela USP/São Paulo; o Programa em Meio Ambiente e Desenvolvimento (Made), originado em 1994, pela UFPR/Paraná; o Programa de Desenvolvimento Sustentável (CDS), da UnB/Brasília, criado em 1995; e o Programa de Pós-Graduação em Desenvolvimento e Meio Ambiente (Prodema), criado em 1996, em rede.

\section{Prodema UFC - experiência interdisciplinar}

O Programa de Pós-Graduação em Desenvolvimento e Meio Ambiente (Prodema), da Universidade Federal do Ceará, faz parte de uma rede de sete universidades concebidas para compreender e incorporar a complexidade do desenvolvimento sustentável nos estudos da região Nordeste do Brasil. Em 1996, o Prodema-Rede foi consolidado, inicialmente, com a participação de seis Instituições de Ensino Superior (IES); no entanto, como afirma Ramalho Filho (1999), sob pressões acadêmicas, as atividades nessas IES foram iniciadas localmente em períodos diferenciados - Universidade Federal de Sergipe (UFS); Universidade Federal do Ceará (UFC); Universidade Regional do Rio Grande do Norte (URRN), em 1995; Universidade Federal da Paraíba (UFPB); conjuntamente com a Universidade Estadual da 
Paraíba (UEPB) em 1996 e Universidade Federal de Alagoas (Ufal) em 1997.

No decorrer dos quase 18 anos do Prodema-Rede, os programas de pós-graduação foram incorporados, enquanto outros foram retirados. Em 2010, com o amadurecimento do curso de mestrado, foi criado o doutorado em Desenvolvimento e Meio Ambiente, que surgiu com uma nova estrutura organizacional - Associação Plena em Rede das Instituições -, incluindo uma coordenação geral, institucionalizada atualmente na UFC, e vários subprogramas a ela subordinados. Hoje, o Prodema-Rede é formado pelas seguintes IES: Universidade Federal do Piauí, Universidade Federal do Ceará, Universidade Federal do Rio Grande do Norte, Universidade Federal da Paraíba, Universidade Federal de Pernambuco, Universidade Federal de Sergipe e Universidade Estadual de Santa Cruz.

A proposta do Prodema-Rede caracteriza-se por conter quatro itens inovadores: a questão do desenvolvimento sustentável na pósgraduação e o caráter interdisciplinar, interinstitucional e intrarregional. A incorporação do conceito de desenvolvimento sustentável ao discurso acadêmico, com preocupações voltadas ao desenvolvimento de uma região historicamente fragilizada, trouxe a perspectiva de um planejamento para médio e longo prazos capaz de beneficiar as futuras gerações. Além disso, a interdisciplinaridade necessária para tal processo tende a quebrar o paradigma da departamentalização nas universidades, incentivando não somente a formação de grupos de pesquisa interdepartamentais, mas possibilitando que os docentes compreendam a importância da pesquisa interdisciplinar.

O caráter interinstitucional, por sua vez, fortalece o programa ao somar as melhores especializações de cada IES enquanto rede, diante de objetos de estudos comuns, abrangendo não somente o seu local, mas uma região, a partir da intrarregionalidade, o que possibilita estudos comparativos e uma maior abrangência de capacidades institucionais. 


\section{a. Contribuições do Prodema-UFC para a sustentabilidade}

O Prodema-UFC iniciou suas atividades com a entrada de sua primeira turma de mestrado em 1995 e com a efetiva participação de professores dos departamentos de Biologia, Economia Agrícola e Geografia dessa instituição. Outros departamentos também contribuíram com recursos humanos de qualidade ao longo do tempo, como foi o caso dos departamentos de Letras, Geologia, Solos, Química, Engenharia Agrícola, Medicina, Engenharia de Pesca e Economia Doméstica. Os departamentos citados são unidades de diferentes centros da Universidade Federal do Ceará: Centro de Ciências, Centro de Ciências Agrárias, Centro de Ciências da Saúde e Centro de Humanidades, o que já fortalece sua predisposição à interdisciplinaridade.

Desde a criação do Prodema até 2012, foram selecionados 287 estudantes, sendo contabilizadas 266 dissertações defendidas (Figura 1).

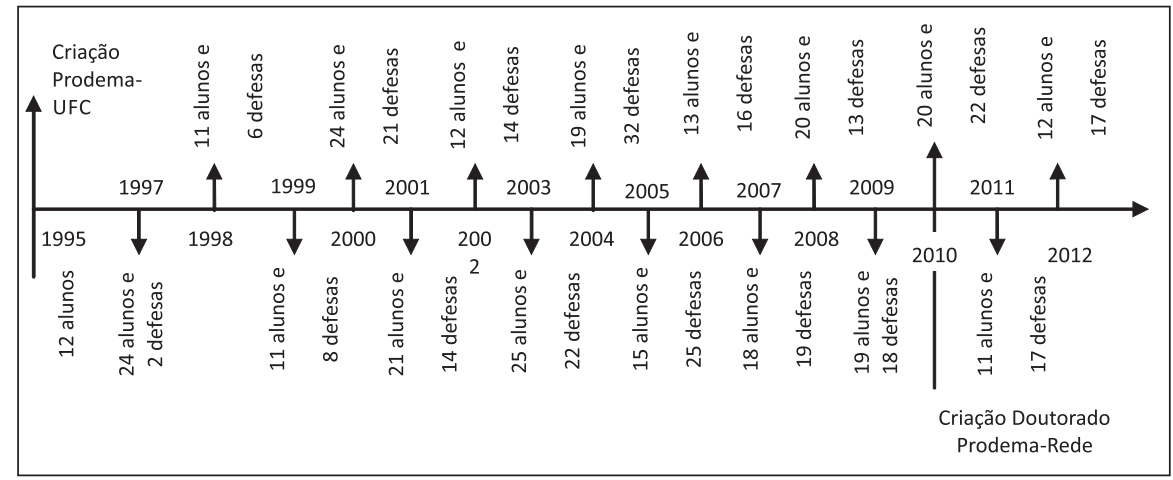

Fonte: Dados do banco de dissertações da UFC, atualizado em julho de 2012.

Figura 1. Linha do Tempo Prodema-UFC

Diversos são os cursos de graduação de origem dos alunos, expondo-se assim a diversidade dos discentes do programa (Figura 2). Profissionais oriundos de 37 diferentes cursos, distribuídos em áreas mais ou menos associadas diretamente às questões ambientais, foram qualificados pelo Prodema-UFC, havendo destaque para os cursos de: Agronomia (24 alunos), Biologia (48 alunos), Direito (25 alunos), Engenharia de Pesca (28 alunos) e Geografia (72), contabilizados no 
período de 1995 a 2012. Com esse perfil, verificam-se quais as áreas que mais buscam a inserção da sustentabilidade na sua profissionalização.

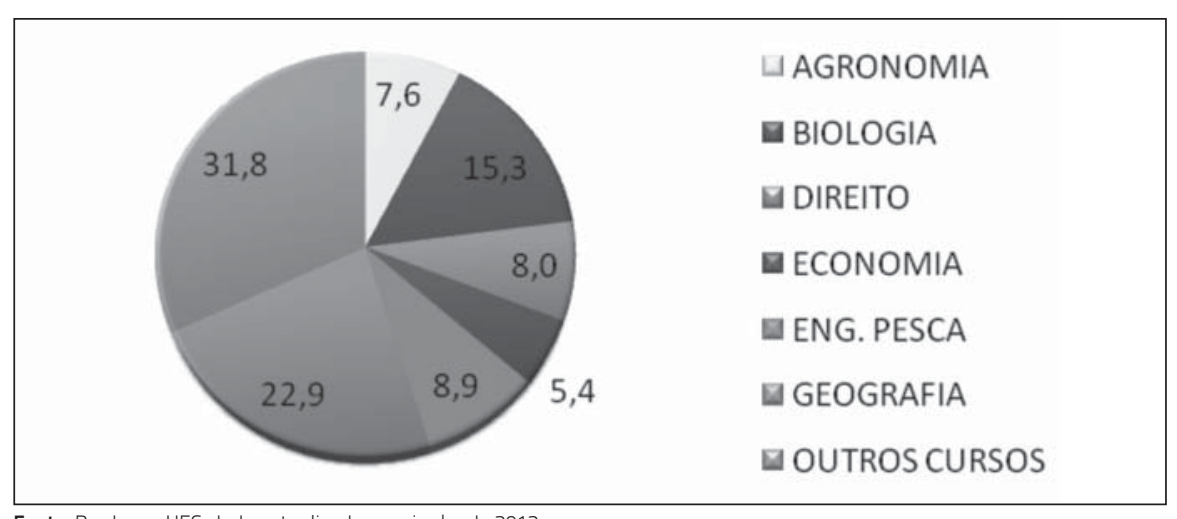

Fonte: Prodema-UFC, dados atualizados em junho de 2012.

Figura 2. Distribuição relativa dos discentes selecionados para o mestrado no Prodema-UFC, segundo o curso de graduação, período 1995 a $2012(\%)$

Vale destacar que em 2004 foi criado o mestrado em Geografia; em 2008, o Programa de Ecologia e Recursos Naturais; e, em 2009, o doutorado em Geografia. E mesmo com essas novas pós-graduações na UFC, que inserem em suas especialidades um viés de sustentabilidade, a busca pela interdisciplinaridade trabalhada pelo Prodema-UFC cresceu. No ano de 2008, dos 20 alunos que entraram, 10 possuíam a graduação em Geografia e três em Biologia.

O conhecimento gerado pela interdisciplinaridade envolve uma subjetividade improvável de ser quantificada. No entanto, a categorização das 266 dissertações defendidas no período de 1997 a 2012, nas diferentes temáticas priorizadas pela Rio+20 - água, cidades sustentáveis, desastres naturais e mudanças climáticas, economia verde e inclusão social, energia sustentável, oceanos, segurança alimentar e agricultura orgânica -, apresenta a contribuição do programa na busca por um modelo mais sustentável para a região (Figura 3). As categorias desenvolvimento rural, formação de recursos humanos e gênero devemse à necessidade regional do programa. 
Rabelo et al. / A experiência do Prodema na pós-graduação brasileira: ciência para a sustentabilidade na UFC

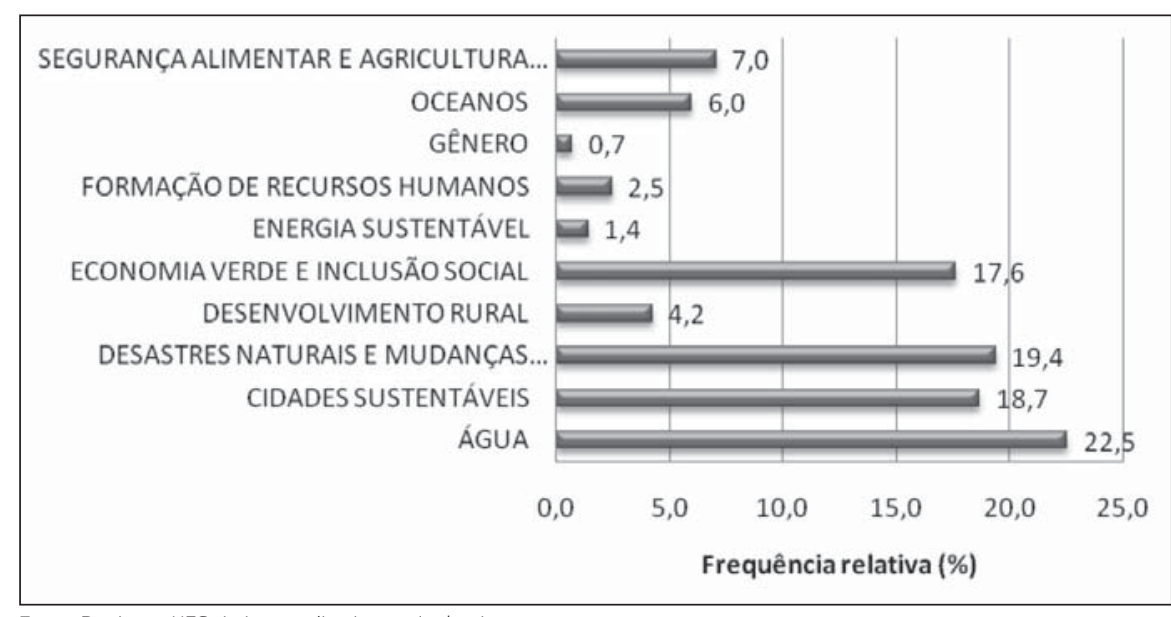

Fonte: Prodema-UFC, dados atualizados em junho de 2012.

Figura 3. Distribuição relativa das dissertações defendidas no ProdemaUFC segundo as temáticas da Rio+20 (turmas de 1995 a 2010)

Esses temas estão intimamente relacionados às vulnerabilidades socioeconômicas e ambientais do estado do Ceará, principal objeto de estudo do programa. A inserção do estado do Ceará no bioma caatinga solicita, para uma convivência com o semiárido, um conhecimento prévio científico que possa subsidiar as tomadas de decisões. Ao longo de sua história, as pesquisas desenvolvidas pelo Prodema-UFC priorizaram as seguintes categorias: água, cidades sustentáveis, desastres naturais e mudanças climáticas e economia verde e inclusão social; inerentes às preocupações locais, essas categorias também se inserem nas atenções globais, ao serem priorizadas na Rio+20. Embora muitas das temáticas trabalhadas pelos mestrandos possam ser incentivadas pelos grupos de pesquisas, liderados pelos docentes, outras já adentram o programa pela necessidade profissional do aluno. Percebe-se assim a contribuição do programa não somente em concretizar um estudo científico sobre objetos de pesquisa que possam inserir essa transição ao desenvolvimento sustentável, mas ao preparar também esse novo profissional, instigando-o criticamente a quebrar paradigmas.

\section{b. Evoluções e limites da interdisciplinaridade}

No Prodema-UFC, são percebidas três dimensões distintas que potencializam a interdisciplinaridade em um curso de pós-graduação: 
uma interação entre os discentes de diferentes formações, entre discentes e docentes e, finalmente, entre docentes.

Atualmente, o quadro de docentes do Prodema-UFC é composto por 24 professores, distribuídos em nove departamentos da Universidade Federal do Ceará: Biologia, Economia Doméstica, Economia Agrícola, Educação, Engenharia Agrícola, Geografia, Geologia, Medicina e Solos. Quanto aos discentes, considerando-se as turmas anuais de 1995 a 2012, são provenientes dos mais diversos cursos de graduação.

A interdisciplinaridade que nasce entre os conhecimentos dos discentes, por meio de suas especialidades, advindas de suas graduações, com os docentes e orientadores - com sua bagagem departamental - é uma das mais complexas. Nesse processo, é obvio que o trabalho acadêmico flui melhor quando a graduação do discente insere-se nas áreas abrangidas pelo departamento do orientador. Contudo, a interdisciplinaridade é mais bem vivenciada quando as áreas aparentam discordância, como, por exemplo, um docente biólogo com um orientador economista. A desconstrução do saber e as dúvidas sobre o objeto de estudo são redescobertas pelos pares, que, em geral, solicitam um terceiro membro - coorientador - para equilibrar o diálogo. Dessa experiência, o discente é quem obtém o melhor resultado interdisciplinar, por ser ele o recurso humano formado na pós-graduação. Embora os docentes também aprendam com as descobertas de seus alunos, um pós-graduado interdisciplinar absorverá melhor, sem preconceitos metodológicos, a fusão de novos olhares para velhos problemas do mundo.

O Prodema-Rede possui duas áreas consideradas no programa como básicas a serem interligadas - a Economia e a Ecologia - pelas suas disciplinas de tronco comum. No mestrado, são três as disciplinas, com ementas, programas e bibliografia básica iguais para a rede e ajustados, a depender das necessidades locais, pelos docentes responsáveis. Nesse formato, as disciplinas são trabalhadas localmente e ministradas geralmente com outro docente local. A função dessas disciplinas não é apenas o de repasse de conhecimentos, mas também a necessidade de uma construção crítica na perspectiva do desenvolvimento sustentável. 
No formato do doutorado, houve um avanço. Por ser institucionalizado perante a Capes, o formato rede possibilita um melhor diálogo entre os docentes e as disciplinas das diversas IES que compõem o Prodema-Rede. O tronco comum é formado por quatro disciplinas, em que três são as mesmas compartilhadas no mestrado e apenas uma é exclusiva do doutorado. Essa disciplina exclusiva é ministrada, anualmente, na IES escolhida para a aula magna do curso, sendo obrigatoriamente trabalhada por no mínimo dois docentes. Esse é um ponto importante a ser mais bem analisado: a interação interdisciplinar entre docentes.

A construção interdisciplinar do curso de mestrado forneceu subsídio ao curso de doutorado para se perceber a importância do "dividir para somar", ao se ministrar uma disciplina a ser trabalhada em um viés interdisciplinar. Se em um curso local se buscava essa interdisciplinaridade entre departamentos, em um curso de rede interinstitucional a interdisciplinaridade vem também com a interdepartamentalização, influenciada pela cultura organizacional da IES de origem do docente.

O planejamento de uma disciplina nesse formato, quando trabalhada de forma local, se dá de forma presencial entre docentes de diferentes departamentos da mesma instituição e de acordo com a proximidade profissional. Porém, quando incorpora docentes de diferentes instituições, como no caso do doutorado, nem sempre existe a proximidade profissional, devido ao tamanho do Prodema-Rede em si. A inserção da interdisciplinaridade nesse formato traz alguns fatores limitantes, entre os quais a própria disciplinaridade dos docentes, além dos valores de formação educacional compartilhados pelas IES de origem desses docentes participantes. Contudo, em ambos os casos, existe dificuldade em encontrar docentes com formação holística e sistêmica.

Para os discentes, a interdisciplinaridade entre docentes de uma mesma instituição traz um novo olhar para a própria instituição, antes vista apenas de forma fechada em seus departamentos, haja vista que a interdisciplinaridade entre docentes de diferentes instituições traz uma riqueza imensurável para o aprendizado, principalmente quando trabalhada por docentes de áreas de conhecimento que aparentemente 
seriam antagônicas. O grande desafio no modelo de pós-graduação interinstitucional são os custos financeiros, principalmente relativos às disciplinas, que requerem o deslocamento físico dos discentes matriculados e respectivos docentes para uma das IES da rede.

O Prodema-UFC não está vinculado a nenhum departamento e não possui nenhum curso de graduação. Sua vinculação com a UFC é diretamente com a Pró-Reitoria de Pesquisa e Pós-Graduação. Esse fator permitia, em seu projeto inicial, que a filosofia do curso perpassasse por qualquer departamento. Contudo, diante de uma estrutura organizacional departamental, em que as alocações de recursos financeiros ou humanos assim também são distribuídos, os 18 anos de programa não foram suficientes para a construção de um espaço físico para o Prodema-UFC.

A não vinculação a um departamento também traz outras variáveis importantes a serem refletidas, principalmente diante da nova demanda pelos cursos de pós-graduação no Brasil, sejam eles inter ou disciplinares. De 1995 até o ano de 2010, houve um grande salto na quantidade de alunos que ingressaram nas universidades, inclusive na busca por um título de mestre ou doutor. Essa demanda também requisita uma maior dedicação do docente a seu departamento de origem. Se o ProdemaUFC não está ligado a nenhum departamento e não possui graduação acoplada, a dedicação de seus docentes tende a ser cada vez menor, diante das urgências departamentais no cumprimento de suas metas com a IES.

Além das disciplinas de tronco comum e das optativas, inserem-se, na estrutura curricular do Prodema-Rede, os seminários integradores, cuja proposta é fornecer um diálogo interdisciplinar entre discentes, docentes e convidados especiais acerca das pesquisas de dissertações e teses dos docentes. São três os números de seminários a constar na proposta, em que o II Seminário Integrador, para o mestrado, e o I Seminário de Tese, para o doutorado, ocorrem ambos em Rede, com a participação de todos os alunos matriculados nesse período, transformando-se em um evento científico regional de todas as IES associadas. Essa "babel acadêmica” possibilita, principalmente entre 
os discentes, o contato com os diversos trabalhos e, muitas vezes, o conhecimento de novas formas metodológicas de analisar objetos de estudos semelhantes.

A visibilidade do Prodema-Rede cresceu em número de alunos e de IES participantes. Hoje, existe a participação de alunos não somente da região Nordeste, mas de todo o Brasil, e, desde 2009, diversos alunos dos países de língua portuguesa, principalmente na UFC, estão internacionalizando o curso, o que torna o desafio interdisciplinar ainda maior, devido à inserção também da variável cultural, que faz parte desse processo.

\section{Conclusões}

A universidade, ao formar recursos humanos e gerar conhecimentos, pode contribuir para a transição do desenvolvimento sustentável, passando do embate teórico-conceitual para a busca de sua aplicabilidade. Precisa-se rever o real papel do ensino superior nessa jornada e habilitar as universidades a se tornarem modelos de práticas sustentáveis transformadoras, inserindo a sustentabilidade na arquitetura de suas instalações físicas, nos modelos de gestão e principalmente em seus currículos de ensino, pesquisa e extensão.

Uma IES que não insere em sua missão a prioridade no desenvolvimento sustentável não pode formar líderes em sustentabilidade ou fazer ciência para a sustentabilidade. Trazer novas respostas tecnológicas e socioeconômicas na resolução de problemas nas áreas de produção e desenvolvimento, entre eles, a transição para o desenvolvimento sustentável, é hoje responsabilidade social das universidades.

A interdisciplinaridade é o ponto de partida na abordagem necessária dessa transição. Adotada por um grupo de pesquisadores desbravadores do Prodema-Rede, desde a década de 1990, verificase, ao longo dessa jornada, que muito se aprendeu com a prática interdisciplinar, não se findando; pelo contrário, transformando-se, com novos e antigos desafios. 
O Prodema-Rede apresenta como diferencial e maior contribuição à experiência da interdisciplinaridade na pós-graduação, como tentativa de aprofundar o debate sobre um dos temas mais discutidos e complexos das últimas décadas, o Desenvolvimento Sustentável.

Ao reunir docentes e discentes com diferentes formações acadêmicas, o Prodema-UFC ultrapassou a expectativa de interdisciplinaridade e criou um ambiente favorável à quebra de paradigmas na formação de recursos humanos ao apontar, por meio de dissertações defendidas, mudanças possíveis nos setores produtivos e na sociedade.

Essa experiência vem contribuindo para inserir a questão do desenvolvimento sustentável nos currículos acadêmicos das universidades. No entanto, há, ainda, grandes desafios. Preparar o novo profissional de sustentabilidade e estimular a criação de ciência e tecnologia capazes de transpor as barreiras existentes para a efetivação da economia verde talvez seja o maior deles. Tal desafio demanda urgência na implementação dos princípios inseridos na Educação para a Sustentabilidade.

Recebido 25/11/2012

Aprovado 25/07/2013

\section{Referências bibliográficas}

AGENDA 21 GLOBAL. Conferência das Nações Unidas sobre Meio Ambiente e Desenvolvimento. Capítulo 36: promoção do ensino, da conscientização e do treinamento. Disponível em: <http://www.mma. gov.br/responsabilidade-socioambiental/agenda-21/agenda-21global/item/716>. Acesso em: 17 jun. 2012

AlvarengA, A. T. de; SOMmerman, A.; AlVAREZ, A. M. de S. Congressos Internacionais sobre Transdisciplinaridade: reflexões sobre emergências e convergências de idéias e ideais na direção de uma nova ciência moderna. Saúde e Sociedade, São Paulo, v. 14, n. 3, set./dez. 2005. 
BÜRGENMEIER, B. Economia do Desenvolvimento Sustentável. Lisboa: Instituto Piaget, 2005.

FAZENDA, I. C. A. Interdisciplinaridade: História, teoria e pesquisa. Campinas, SP: Papirus, 1994.

FOLLAN, R. A. Interdisciplinaridade e Dialética: sobre um mal-entendido. In: FRIGOTTO, G. et al. Interdisciplinaridade: para além da filosofia do sujeito. Petrópolis, RJ: Vozes, 1995. p.127-141.

GROOT. H. T. de. Environmental science Theory. Concepts and methods in a one-world, problem-oriented paradigm. Centre for Environmental Studies. University of Leiden. Netherlands: Elsevier, 1992.

JAPIASSU, H. Dicionário Básico de Filosofia. 4 ed. atual. Rio de Janeiro: Jorge Zahar Ed., 2006.

KLEIN, J. T. Interdisciplinarity: history, theory and practice. Detroit, Michigan: Wayne State University Press, 1990.

LEFF, E. Complexidade, Interdisciplinaridade e Saber Ambiental. In: PHILIPPI JR, A. Interdisciplinaridade em Ciências Ambientais. São Paulo: Signus Editora, 2000. p. 19-51.

. Epistemologia ambiental. São Paulo: Cortez, 2002.

LEFF, E.; MONTES, J. M. Los problemas del conocimiento y la perspectiva ambiental del desarrollo. Mexico: Siglo Veintiuno, 1986.

MANGINI, F. N. da R.; MIOTO, R. C. T. A interdisciplinaridade na sua interface com o mundo do trabalho. Revista Katálysis, Florianópolis, v. 12, n. 2, p. 207-215, dez. 2009.

MINAYO, M. C. S. Interdisciplinaridade: funcionalidade ou utopia? Saúde e Sociedade, v. 3, n. 2, p. 42-64, 1994.

MORIN, E. Os sete saberes necessários à educação do futuro. 2. ed. São Paulo: Cortez; Brasília, DF: UNESCO, 2000. 
PAVIANI, J. Interdisciplinaridade: conceitos e distinções. 2 ed. Caxias do Sul, RS: Edusc, 2008.

PENA-VEGA, A.; ALMEIDA, E. P. de. 0 pensar complexo: Edgar Morin e a crise da modernidade. Rio de Janeiro: Garamond, 1999.

PIMENTA, C. Contributos para a elaboração de uma tese interdisciplinar. Revista do Centro de Educação e Letras, v. 10, n. 1, p. 63-77, 2008.

POMBO, O. Interdisciplinaridade e integração dos saberes. Liine em Revista, v. 1, n. 1, p. 3-15, mar. 2005.

POMBO, O.; LEVY, T.; GUIMARÃES, H. A interdisciplinaridade: reflexão e experiência. 1. ed. Lisboa: Ed. Texto, 1993.

RAMALHO FILHO, R. A. Seminário Fundacional: Desenvolvimento e Meio Ambiente - Agenda 21 para o Nordeste do Brasil. Maceió: Prodema/ Ufal, 1999. 431p.

REPKO, A. F. Interdisciplinary research: process and theory. 2. ed. USA: Sage, 2012.

ROHDE, G. M. Epistemologia Ambiental: uma abordagem filosóficocientífica sobre a efetivação humana alopoiética da Terra e de seus arredores planetários. 2 ed. rev. e ampl. Porto Alegre: EDIPUCRS, 2005.

ROSSATO, R. Universidade: nove séculos de história. Passo Fundo: Ediupf, 1998.

TOZONI-REIS, M. F. C. Educação ambiental: natureza, razão e história. Campinas, SP: Autores Associados, 2004.

TRINDADE, D. F. Interdisciplinaridade: um novo olhar sobre as ciências. In: FAZENDA, I. 0 que é interdisciplinaridade? São Paulo: Cortez, 2008. p. $65-84$. 
UNESCO. Década da Educação das Nações Unidas para um Desenvolvimento Sustentável, 2005-2014: documento final do esquema internacional de implementação. Brasília: UNESCO/ OREALC, 2005.

. The UN Decade of Education for Sustainable Development (DESD 2005-2014). The First Two Years. Paris: UNESCO, 2007.

Global Higher Education for Sustainability Partnership (GHESP). 2012. Disponivel em:<http://portal.unesco.org/education/en/ev.phpURL_ID=34701\&URL_DO=DO_TOPIC\&URL_SECTION=201.html>. Acesso em: 05 set. 2012.

UNESCO/UNEP. Interdisciplinary Approaches in Environmental Education. Environmental Education Series 14. Paris: UNESCO/UNEP, 1985. 